\title{
Embelin inhibits abdominal aortic aneurysm through decreasing IL-6-induced STAT3 and NF-кB inactivation
}

\author{
QIANG LIU ${ }^{1}$, QINGSHAN WANG ${ }^{2}$ and HAIBIN LI ${ }^{1}$ \\ ${ }^{1}$ Department of Vascular Surgery, The First Hospital of Qiqiha'er City, Qiqiha'er, Heilongjiang 161005; \\ ${ }^{2}$ Department of Vascular Surgery, Heilongjiang Provincial Hospital, Harbin, Heilongjiang 150036, P.R. China
}

Received December 22, 2015; Accepted September 2, 2016

DOI: $10.3892 / \mathrm{mmr} .2018 .9221$

\begin{abstract}
The aim of the present study was to investigate the effect of embelin on abdominal aortic aneurysm (AAA). AAA model mice were induced by chronic infusion of $1,000 \mathrm{ng} / \mathrm{kg} / \mathrm{min}$ Angiotensin II. AAA model mice were treated with 25,50 or $100 \mathrm{mg} / \mathrm{kg}$ embelin for 28 days. Embelin inhibited tumor necrosis factor- $\alpha$, interleukin (IL)-1 $\beta$, IL-6, IL-18 and malondialdehyde (MDA) level activities, increased superoxide dismutase, glutathione (GSH) and GSH peroxidase level activities and inhibited MDA level activities in AAA mice Embelin suppressed the secretion of matrix metalloproteinase- 9 protein expression, monocyte chemoattractant protein-2 activity and epithelial neutrophil-activating peptide expression levels in AAA mice. Embelin suppressed phosphorylated-signal transducer and activator of transcription (STAT) 3, phosphorylated-p38 mitogen-activated protein kinase and nuclear factor $(\mathrm{NF})-\kappa \mathrm{B}$ protein expression in AAA mice. These findings indicate that embelin inhibits AAA through decreasing IL-6-induced STAT3, and NF- $\mathrm{B}$ inactivation.
\end{abstract}

\section{Introduction}

Abdominal aortic aneurysm (AAA) is the most common true aneurysm, with a high tendency of rupture following occurrence, resulting in its being classified as a serious threat to human health (1). Since the formation of this condition is a typically long process, for the majority of AAA cases, there are no obvious clinical symptoms at the early stage, and abdominal aortic aneurysm is finally diagnosed at the early stage of arterial expansion (2). From the perspective of aneurysm accumulation range, almost all the AAA cases are associated with infrarenal aorta, and only $5 \%$ involve the

Correspondence to: Dr Qingshan Wang, Department of Vascular Surgery, Heilongjiang Provincial Hospital, 82 Zhongshan Street, Harbin, Heilongjiang 150036, P.R. China

E-mail:wfexdqkt98@126.com

Key words: embelin, abdominal aortic aneurysm, interleukin-6, signal transducer and activator of transcription 3 , nuclear factor- $\kappa \mathrm{B}$ renal aorta (2,3). A total of $25 \%$ of the AAA cases may be the invasion of the medullary artery, however isolated skeletal aneurysm is relatively rare, and isolated suprarenal AAA cases are rarer, unless the invasion of the thoracic aorta or renal abdominal aorta results in chest AAA (4).

Interleukin (IL)-6 is a primary multifunctional pro-inflammatory cytokine, secreted by a variety of cell types, including T lymphocytes, B lymphocytes, monocytes, epithelial cells and certain tumor cells, involved in inflammation and the immune response, which affect cell survival, proliferation and apoptosis (5). It results in neutrophil infiltration by regulating the expression of chemokines and adhesion molecules and recruiting mononuclear macrophage accumulation to release a large number of cytokines and growth factors to maintain the continuity of inflammation and to promote the development of multiple tumors, including the growth of neuroblastoma, cervical cancer and angiogenesis (6).

It has previously been demonstrated that the effect of IL-6 is associated with various signaling pathways, particularly the signal transducer and activator of transcription (STAT) signaling pathway (6). This is the primary pathway that results in IL-6 promoting various biological effects, including local tumor inflammation, angiogenesis and expression of genes that have an impact on cell cycle, and in the family of STAT transcription factors, STAT3 is the most important (7). STAT3 transcription factor is an oncogene, which exhibits an important role in the regulation of inflammation and the immune response, and it is highly expressed and aberrantly activated in breast, colon and prostate cancers, AAA and other tumors (8). The persistent activation of STAT3 is closely associated with tumor formation, and promotion of tumor cell proliferation, angiogenesis, invasion and metastasis, therefore inhibiting the expression and activation of STAT3 may inhibit tumor growth significantly (9). Previous studies have demonstrated that there is an interaction between STAT3 and nuclear factor (NF)- $\kappa \mathrm{B}$ signaling pathways, which jointly promote tumor development $(8,10)$. NF- $\kappa \mathrm{B}$ is a key molecule in regulating inflammation and immune responses, is a hub for the regulation of inflammatory gene expression, and also a cancer gene expressed highly in multiple tumors and activated abnormally to regulate cell growth, apoptosis, angiogenesis, invasion and metastasis (11).

Embelin is the primary component of white acid vine fruit (12). This plant is traditionally used as the first-line 
anti-inflammatory drug to relieve rheumatism and fever. Relevant research revealed that embelin also has antioxidant, hepato-protective, antibacterial, anti-diabetic, and anti-inflammatory effects in other organs $(12,13)$. Embelin additionally blocks the NF-KB signaling pathway that is the key protein associated with the ischemia-reperfusion injury-induced inflammatory response (14). The aim of the present study was to elucidate how embelin inhibits AAA and its underlying molecular mechanism.

\section{Materials and methods}

Animals, animal groups and Angiotensin II-induced AAA in mice. All animal experiment operations were conducted according to nursing and use guidance for animal experiment operations of National Institutes of Health in Heilongjiang Provincial Hospital (15). Male, C57BL/6 mice (20-22 g; 6 weeks old, $n=38$ ) were purchased from Animal laboratory of Harbin Medical University (Harbin, Heilongjiang, China) and were raised in a laboratory animal room with a $12 \mathrm{~h}$ light/dark cycle at $24 \pm 2^{\circ} \mathrm{C}, 50-60 \%$ humidity, and free access to food and water. All mice were randomly distributed into sham group $(\mathrm{n}=6)$, AAA model group $(\mathrm{n}=8)$ and low embelin (25 mg/kg, $\mathrm{n}=8)$, medium embelin $(50 \mathrm{mg} / \mathrm{kg}, \mathrm{n}=8)$ and high embelin $(100 \mathrm{mg} / \mathrm{kg}, \mathrm{n}=8)$ treatment groups. AAA model mice were induced by chronic infusion of $1,000 \mathrm{ng} / \mathrm{kg} / \mathrm{min}$ Angiotensin II using mini-osmotic pumps (cat. no. 1004, Alzet; Durect Corporation, Cupertino, CA, USA). AAA model mice were gavaged with normal saline, and embelin treatment groups were gavaged with 25, 50 and $100 \mathrm{mg} / \mathrm{kg}$ of Embelin. Following 28 days, mice were sacrificed. The experiments were approved by the Animal Ethical and Welfare Committee of the First Hospital of Qiqiha'er (Qiqiha'er, China).

Toluidine blue staining. Mice were anesthetized using $50 \mathrm{mg} / \mathrm{kg}$ of sodium pentobarbital (intraperitoneally) and the aortas were immediately separated and washed with PBS. Samples were perfused with $4 \%$ paraformaldehyde for $30 \mathrm{~min}$ at room temperature. Samples were embedded using paraffin and cut into 5-6 $\mu \mathrm{m}$ sections. Sections were deparaffinized and rehydrated in a descending ethanol series and Tissue-Clear ${ }^{\circledR}$ (Sakura Finetek UK Ltd, Thatcham, England). Then, sections were stained in toluidine blue working solution for $15 \mathrm{~min}$ at room temperature and dehydrated using several degradations of ethanol. Samples were normalized to aortic vessel wall area $\left(\mathrm{mm}^{2}\right)$ and total numbers per aorta since they were few in number.

ELISA analysis. Aortic tissues from mice treated with or without embelin were acquired, and expression levels tumor necrosis factor (TNF)- $\alpha$, interleukin (IL)-1 $\beta$, IL-6, IL-18, in addition to superoxide dismutase (SOD), malondialdehyde (MDA) activities, and monocyte chemoattractant protein (MCP)-2 and epithelial neutrophil-activating peptide (CXCL5) secretions were measured. Aortic tissues $(10 \mathrm{mg})$ were homogenized with radioimmunoprecipitation assay (RIPA) lysis buffer (Beyotime Institute of Biotechnology, Haimen, China) and centrifuged at $14,000 \mathrm{x} \mathrm{g}$ at $4^{\circ} \mathrm{C}$ for $10 \mathrm{~min}$ to collect protein extract. TNF- $\alpha$ (E-EL-M0049c), IL-1 $\beta$ (E-EL-M0037c), IL-6 (E-EL-M0044c), IL-18 (E-EL-M0730c), SOD
(E-EL-M2398c), MDA (E-EL-0060c), GSH (E-EL-0026c), GSH-PX (E-EL-M0950c), MCP-2 (E-EL-H1158c) and CXCL5 (E-EL-M0471c) activities were evaluated using ELISA kits (all from Elabscience Biotechnology Co., Ltd. Wuhan, China).

Western blot analysis. Aortic tissues $(50 \mathrm{mg})$ was homogenized with RIPA lysis buffer (Beyotime Institute of Biotechnology) and centrifuged at $14,000 \mathrm{x} \mathrm{g}$ at $4^{\circ} \mathrm{C}$ for $10 \mathrm{~min}$ to collect protein extract. Protein was quantitated with BCA assay (Beyotime Institute of Biotechnology) and $50 \mu \mathrm{g}$ protein was separated on 10\% SDS-PAGE gels and blotted onto a nitrocellulose membrane. Membranes were blocked using $5 \%$ skimmed milk powder in Tris buffered Tween-20 and incubated with primary antibodies against matrix metallopeptidase (MMP)-9 (13667; 1:2,000; Cell Signaling Technology, Inc., Danvers, MA, USA), phosphorylated (p)-STAT3 (9145; 1:1,000; Cell Signaling Technology, Inc., Danvers, MA, USA), p-p38 (4511; 1:1,000; Cell Signaling Technology, Inc.), NF-кB (8242; 1:2,000; Cell Signaling Technology, Inc.) and GAPDH (AF1186; 1:5,000; Beyotime Institute of Biotechnology) at $4^{\circ} \mathrm{C}$ for $12-16 \mathrm{~h}$. Anti-rabbit $\operatorname{IgG}$ conjugated to horseradish peroxidase secondary antibody (7074; 1:5,000; Cell Signaling Technology, Inc.) was incubated with the membranes at $37^{\circ} \mathrm{C}$ for $1 \mathrm{~h}$. Membranes were visualized using enhanced chemiluminescence Prime Western blotting reagent (GE Healthcare Life Sciences) and ImageLab version 3.0 (Bio-Rad Laboratories, Inc., Hercules, CA, USA) was used for densitometry.

Statistical analysis. Data are expressed as the mean \pm standard deviation using SPSS version 17.0 (SPSS, Inc., Chicago, IL, USA). Multigroup comparisons were assessed using one-way analysis of variance and Tukey's post hoc test. $\mathrm{P}<0.05$ was considered to indicate a statistically significant difference.

\section{Results}

Embelin inhibits AAA incidence rate in Angiotensin II infused mice. The present study first examined the effect of embelin (Fig. 1) on AAA incidence rate in mice. It was demonstrated that that AAA incidence rate was markedly increased in the AAA model group, compared with sham group (Fig. 2). Treatment with embelin significantly inhibited the AAA incidence rate in mice compared with the AAA model group (Fig. 2).

Embelin inhibits vascular remodeling in Angiotensin II infused mice. Next, the effect of embelin was examined on AAA-induce vascular remodeling. As presented in Fig. 3, the thickness of edge leading aortic diameter and aortic wall thickness in the AAA model group were significantly promoted, compared with sham group. Treatment with embelin significantly inhibited edge leading aortic diameter and aortic wall thickness in AAA mice, compared with AAA model group (Fig. 3).

Embelin inhibits inflammatory reaction in Angiotensin II infused mice. The present study analyzed the anti-inflammatory effect of embelin in Angiotensin II infused mice. In Angiontensin II-induced AAA mice, TNF- $\alpha$, IL-1 $\beta$, IL- 6 and IL-18 expression levels were significantly increased compared with control group (Fig. 4). Notably, treatment with embelin 


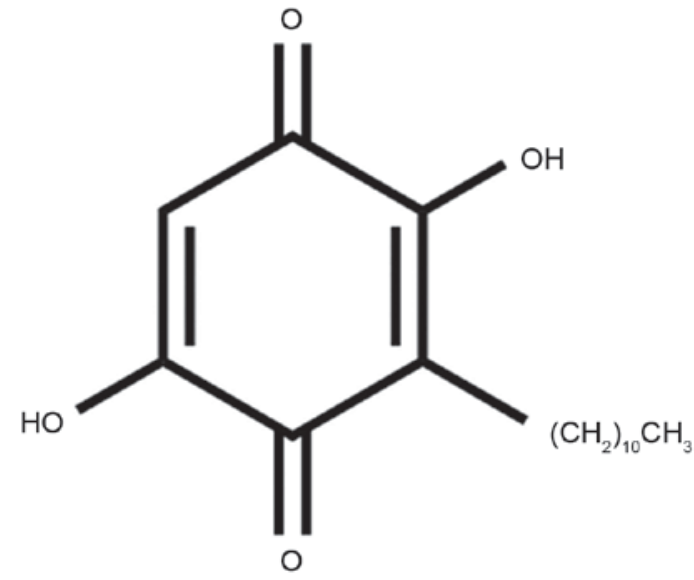

Figure 1. Chemical structure of embelin.

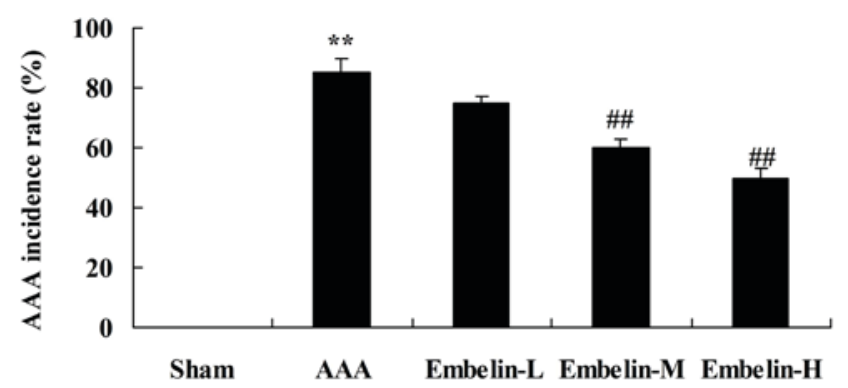

Figure 2. Embelin inhibits AAA incidence rate in Angiotensin II infused mice. AAA model mice were induced by chronic infusion of $1,000 \mathrm{ng} / \mathrm{kg} / \mathrm{min}$ Angiotensin II and gavaged with differing concentrations of embelin or normal saline. ${ }^{* *} \mathrm{P}<0.01$ vs. sham group; ${ }^{\# \#} \mathrm{P}<0.01$ vs. AAA model group. Sham, sham group; AAA, abdominal aortic aneurysm model group Embelin-L, low embelin treatment group ( $25 \mathrm{mg} / \mathrm{kg})$; Embelin-M, medium embelin treatment group $(50 \mathrm{mg} / \mathrm{kg})$; Embelin-H, high embelin treatment group $(100 \mathrm{mg} / \mathrm{kg})$.

suppressed TNF- $\alpha$, IL-1 $\beta$, IL-6 and IL-18 levels in AAA mice compared with AAA model group (Fig. 4).

Embelin inhibits oxidative stress in Angiotensin II infused mice. The present study next investigated the effects of embelin on oxidative stress injury in Angiotensin II infused mice. It was observed that SOD, GSH and GSH-Px level activities were markedly decreased and MDA level activities in model group were markedly increased compared with sham group (Fig. 5). Embelin treatment significantly increased SOD, GSH and GSH-PX level activities and inhibited MDA level activities in AAA mice compared with AAA model group (Fig. 5).

Embelin inhibits MMP-9 and p-STAT3 protein expression in Angiotensin II infused mice. It has previously been demonstrated that MMP-9 regulates inflammatory factors in AAA model mice, therefore the present study investigated the effect of embelin on MMP-9 and p-STAT3 protein expression. As presented in Fig. 6, there was a significant increase of MMP-9 protein expression in the AAA model group, compared with the sham group. In AAA mice, embelin treatment significantly suppressed the MMP-9 and p-STAT3 protein expression levels, compared with the AAA model group (Fig. 6).
Embelin inhibits MCP-2 activity and CXCL5 levels in Angiotensin II infused mice. In order to identify MCP-2 activity and CXCL5 levels in Angiotensin II infused mice, the present analyzed the effect of embelin these factors in the AAA model group. MCP-2 activity and CXCL5 levels were significantly increased in AAA model mice, compared with sham group (Fig. 7). Treatment with embelin significantly inhibited MCP-2 activity and CXCL5 levels in AAA model mice, compared with AAA model group (Fig. 7).

Embelin inhibits p-p38 and $N F-\kappa B$ protein expression in Angiotensin II infused mice. The anti-inflammation mechanism of embelin was investigated in AAA model mice, via p-p38 and $N F-\kappa B$ protein expression quantification with western blot analysis. As presented in Fig. 8 it was observed that $\mathrm{p}-\mathrm{p} 38$ and $\mathrm{NF}-\kappa \mathrm{B}$ protein expression in AAA model group was notably increased compared with sham group. Compared with AAA model group, p-p38 and NF- $\kappa$ B protein expression levels were significantly suppressed in AAA mice treated with embelin (Fig. 8).

\section{Discussion}

There is an extensive difference in AAA prevalence in different regions, with increased European and American populations presenting with the condition compared with in Africa and Asia (16). In 2010, Danish research results revealed that the AAA prevalence rate was $\sim 4.0 \%$; a large-scale conducted among 310 million people in the United States in the same year revealed that the AAA prevalence rate was $1.4 \%$; two large screening studies in Australia with the interval of 9 years indicated that the rates were 4.0 and $7.2 \%$, respectively (16). In Asian countries, a hospital-based study that started in South Korea demonstrated that AAA prevalence rate was $0.43 \%$ in 2009 , significantly lower compared with the European population, which was similar to the results obtained from the screening program carried out in Japan in 2000 (17,18). In the present study, it was demonstrated that embelin significantly inhibited the AAA incidence rate, and decreased edge leading aortic diameter and aortic wall thickness in AAA mice.

Lymphocytes and mononuclear cell infiltration indicated that the autoimmune reaction is important in the formation of AAA (19). Infection is one of the factors for AAA formation, and it has been reported that $55 \%$ of AAA patients suffer from mycoplasma pneumonia (20). In the formation of AAA, the active oxygen species and antioxidants also exhibit an important role (21). The superoxide level in AAA tissues exhibits a 2.5-fold increase compared with the neighboring non-aneurysmal tissue, and a 10-fold increase compared with in normal tissue (22). A total of two days following the injection of aggressive porcine pancreatic elastase in the arterial wall, inducible nitric oxide synthase exhibits a 50-fold increase. Compared with the control saline group, 10 days following the injection of elastase in arterial wall, the expression of the antioxidant SOD exhibits a 20-fold decrease (22). In vitro studies demonstrate that the active oxygen species may activate MMP. Therefore, the imbalance of promotion of the oxidation gene expression is important in human AAA and experimental aneurysm. Reactive oxygen species also affect apoptosis and promote the formation of AAA (23). 

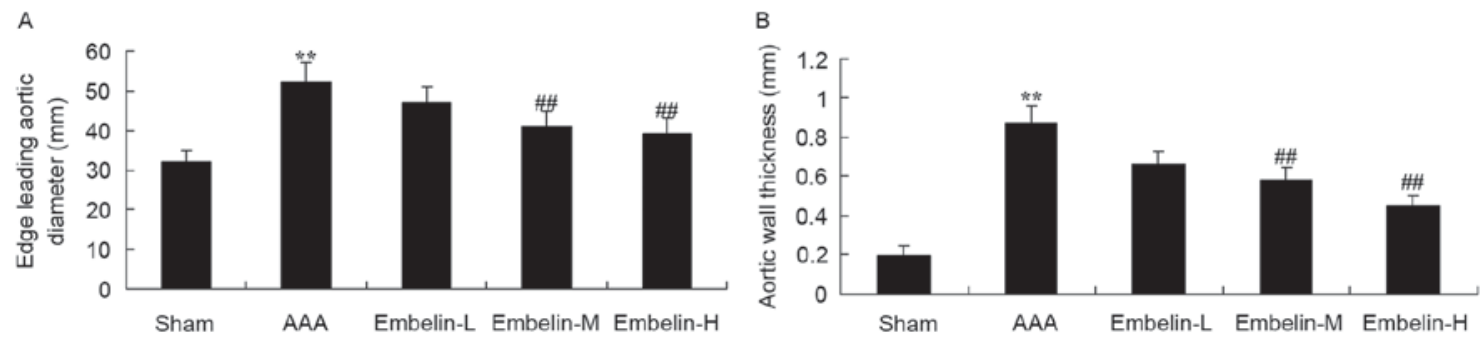

Figure 3. Embelin inhibits vascular remodeling in Angiotensin II infused mice. Embelin inhibited (A) edge leading aortic diameter and (B) aortic wall thickness in Angiotensin II infused mice. ${ }^{* *} \mathrm{P}<0.01$ vs. sham group; ${ }^{\# \#} \mathrm{P}<0.01$ vs. AAA model group. Sham, sham group; AAA, abdominal aortic aneurysm model group; Embelin-L, low embelin treatment group ( $25 \mathrm{mg} / \mathrm{kg})$; Embelin-M, medium embelin treatment group (50 mg/kg); Embelin- $\mathrm{H}$, high embelin treatment group $(100 \mathrm{mg} / \mathrm{kg})$.

A

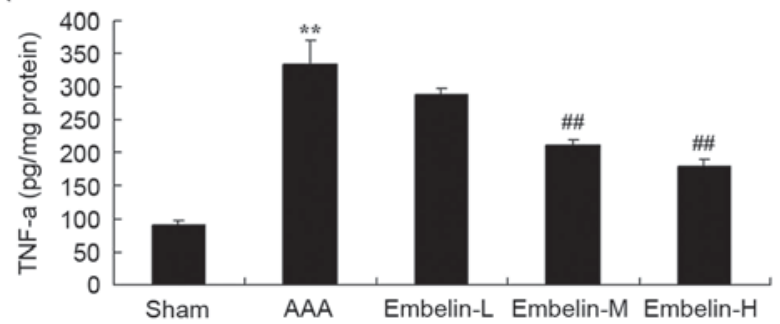

C

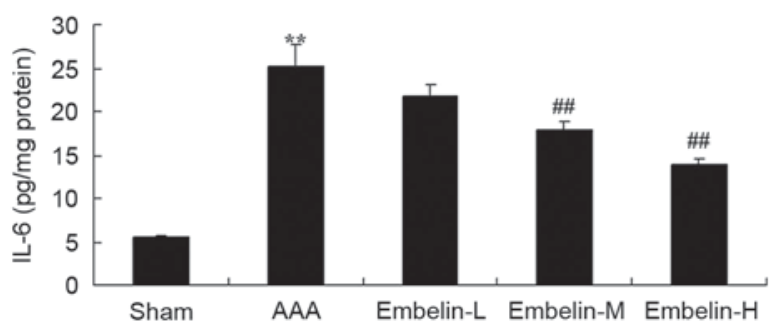

B
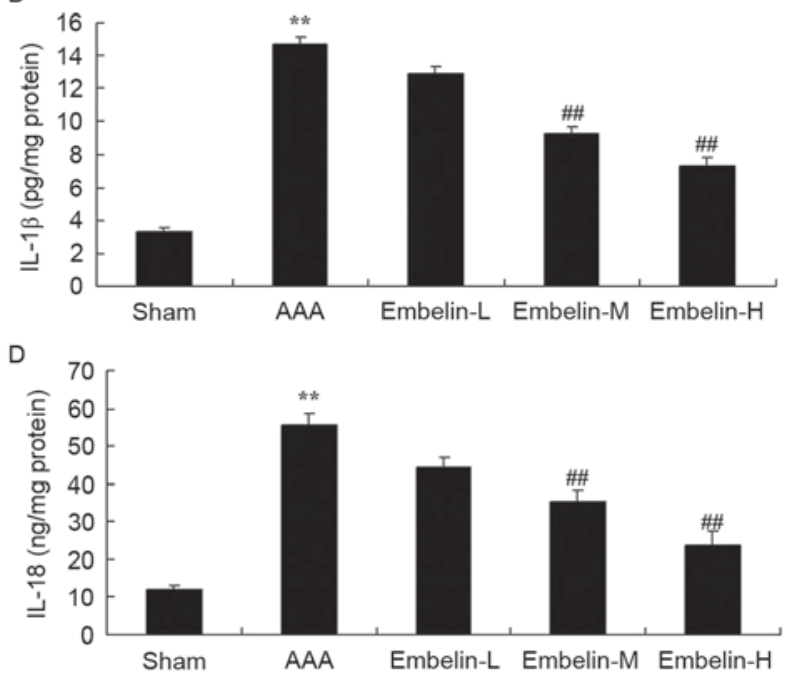

Figure 4. Embelin inhibits inflammatory reactions in Angiotensin II infused mice. Embelin inhibited (A) TNF- $\alpha$, (B) IL-1 $\beta$, (C) IL-6 and (D) IL-18 in Angiotensin II infused mice. ${ }^{* *} \mathrm{P}<0.01$ vs. sham group; ${ }^{\# /} \mathrm{P}<0.01$ vs. AAA model group. Sham, sham group; AAA, abdominal aortic aneurysm model group; Embelin-L, low embelin treatment group $(25 \mathrm{mg} / \mathrm{kg})$; Embelin-M, medium embelin treatment group $(50 \mathrm{mg} / \mathrm{kg}) ;$ Embelin- $\mathrm{H}$, high embelin treatment group $(100 \mathrm{mg} / \mathrm{kg}) ; \mathrm{TNF}-\alpha$, tumor necrosis factor- $\alpha$; IL, interleukin.
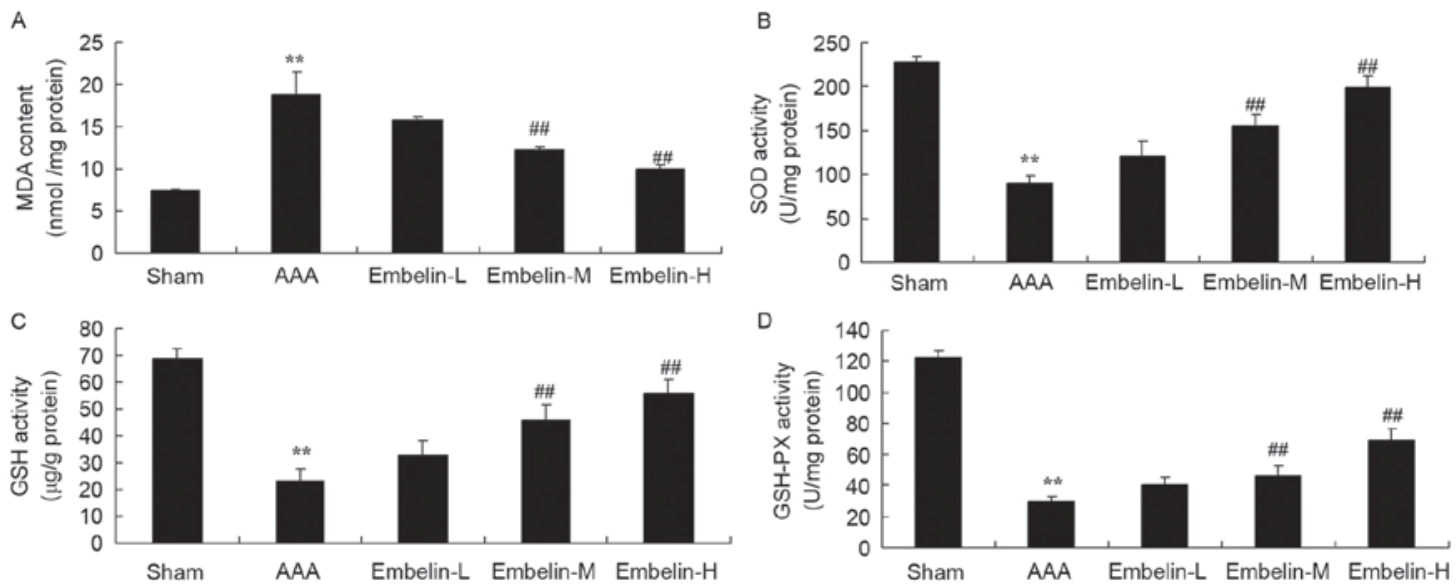

Figure 5. Embelin inhibits oxidative stress in Angiotensin II infused mice. Embelin inhibited (A) MDA and increased (B) SOD, (C) GSH and (D) GSH-PX in Angiotensin II infused mice. ${ }^{* *} \mathrm{P}<0.01$ vs. sham group; ${ }^{* \prime} \mathrm{P}<0.01$ vs. AAA model group. Sham, sham group; AAA, abdominal aortic aneurysm model group; Embelin-L, low embelin treatment group $(25 \mathrm{mg} / \mathrm{kg})$; Embelin-M, medium embelin treatment group $(50 \mathrm{mg} / \mathrm{kg})$; Embelin- $\mathrm{H}$, high embelin treatment group $(100 \mathrm{mg} / \mathrm{kg}) ;$ MDA, malondialdehyde; SOD, superoxide dismutase; GSH, glutathione; GSH-PX, glutathione peroxidase.

In the present study, it was demonstrated that embelin treatment significantly increased SOD, GSH and GSH-PH and inhibited MDA activities in AAA mice.
The incidence of AAA is quite a complex process, which is associated with various factors. The AAA lesion structure is characterized by the damage of elastin and collagen in the 
A

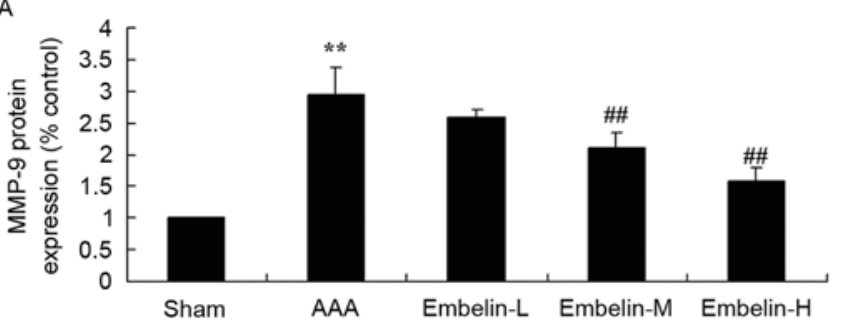

C
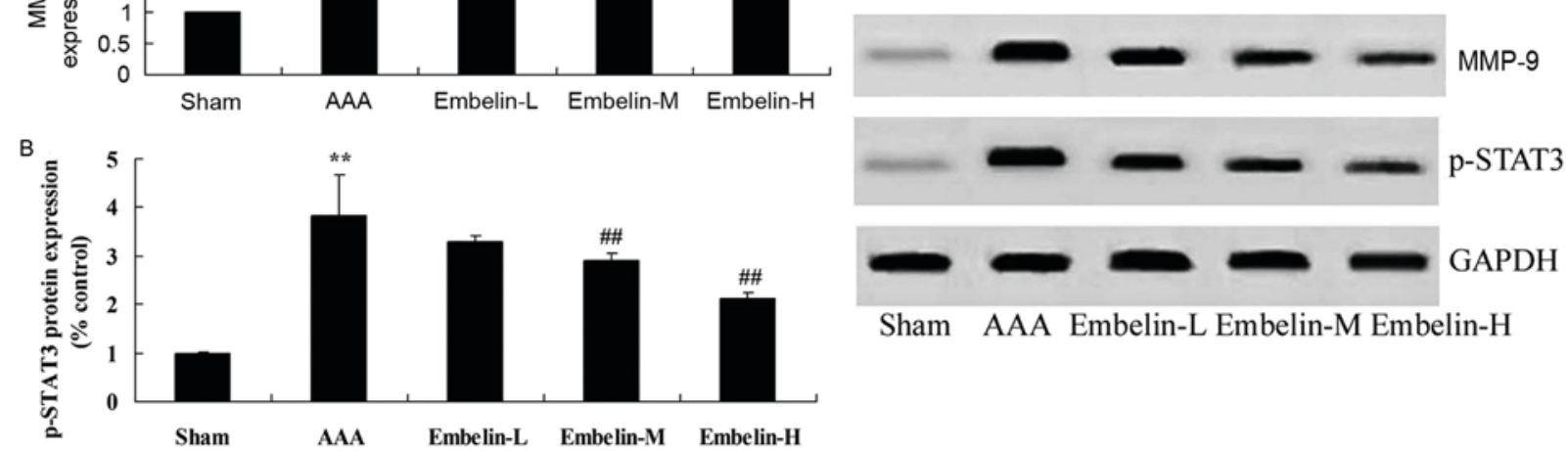

Sham AAA Embelin-L Embelin-M Embelin-H

Figure 6. Embelin inhibits MMP-9 and p-STAT3 protein expression in Angiotensin II infused mice. (A and B) Quantitative analysis and (C) representative image of MMP-9 and p-STAT3 protein expression levels, detected by western blotting assay, in Angiotensin II infused mice. ${ }^{* *} \mathrm{P}<0.01$ vs. sham group; ${ }^{\#} \mathrm{P}<0.01$ vs. AAA model group. Sham, sham group; AAA, abdominal aortic aneurysm model group; Embelin-L, low embelin treatment group (25 mg/kg); Embelin-M, medium embelin treatment group (50 mg/kg); Embelin-H, high embelin treatment group (100 mg/kg); MMP-9, matrix metallopeptidase-9; p, phosphorylated; STAT3, signal transducer and activator of transcription 3.
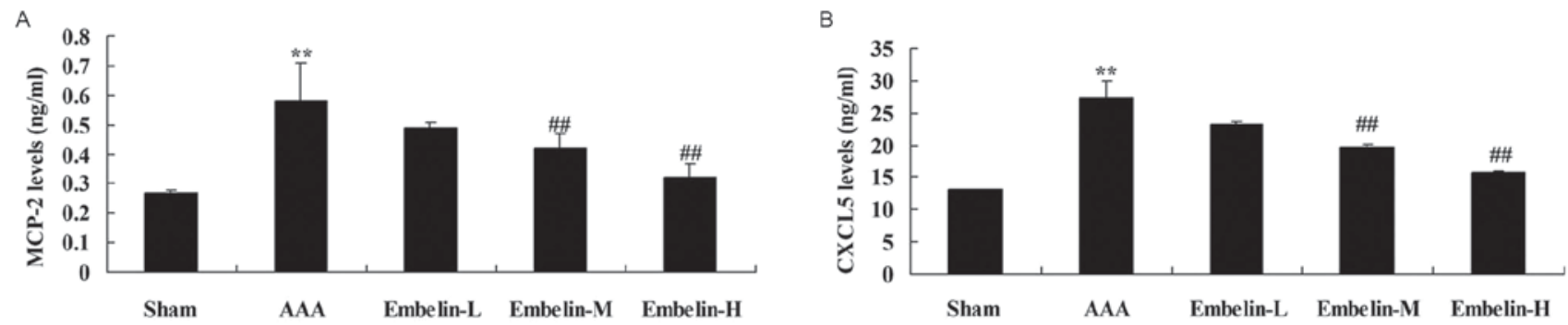

Figure 7. Embelin inhibits MCP-2 activity and CXCL5 levels in Angiotensin II infused mice. Embelin inhibited (A) MCP-2 activity and (B) CXCL5 levels in Angiotensin II infused mice. ${ }^{* *} \mathrm{P}<0.01$ vs. sham group; ${ }^{\# /} \mathrm{P}<0.01$ vs. AAA model group. Sham, sham group; AAA, abdominal aortic aneurysm model group; Embelin-L, low embelin treatment group $(25 \mathrm{mg} / \mathrm{kg})$; Embelin-M, medium embelin treatment group $(50 \mathrm{mg} / \mathrm{kg}) ;$ Embelin- $\mathrm{H}$, high embelin treatment group $(100 \mathrm{mg} / \mathrm{kg}) ; \mathrm{MCP}-2$, monocyte chemoattractant protein; CXCL5, epithelial neutrophil-activating peptide.
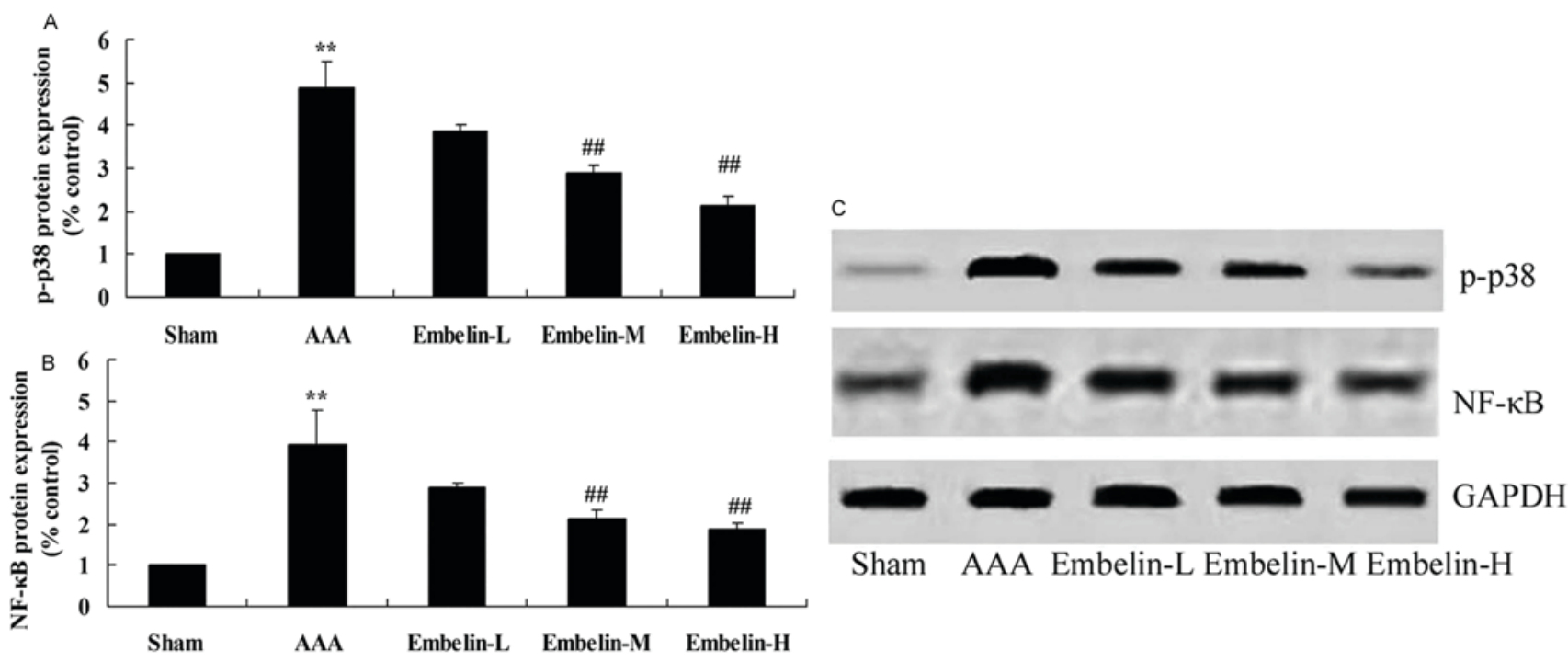

Sham AAA Embelin-L Embelin-M Embelin-H

Figure 8. Embelin inhibits p-p38 and NF- $\mathrm{kB}$ protein expression in Angiotensin II infused mice. (A and B) Quantitative analysis and (C) representative image of p-p38 and NF- $\mathrm{kB}$ protein expression levels, detected by western blotting assay, in Angiotensin II infused mice. ${ }^{* *} \mathrm{P}<0.01 \mathrm{vs}$. sham group; ${ }^{\# \#} \mathrm{P}<0.01$ vs. AAA model group. Sham, sham group; AAA, abdominal aortic aneurysm model group; Embelin-L, low embelin treatment group ( $25 \mathrm{mg} / \mathrm{kg}$ ); Embelin-M, medium embelin treatment group (50 mg/kg); Embelin-H, high embelin treatment group (100 mg/kg); p, phosphorylated; NF- $\mathrm{BB}$, nuclear factor-кB. 
middle wall and outer membrane. Smooth muscle cell degradation resulted in the thinning of the middle layer, and leads to lymphocyte and macrophage infiltration (22). The significant histological feature of AAA is the extensive infiltration of lymphocytes and macrophages in the vessel wall, which leads to generation of cytokines (including interleukins, TNF, immunoreactive fibronectin) and immunoglobulin increase in the aneurysm wall, and these cytokines may lead to the activation of various proteases (24). Although the initiating factors of white blood cell infiltration and transfer are not entirely clear, the denaturation product of elastic protein in the exposed artery walls may be used as a chemokine for macrophage infiltration (25).

Various factors, including IL-6, IL-8 and granulocyte chemotactic protein 2 , may collect and activate various inflammatory cells, particularly neutrophils, thereby mediating inflammation, so as to affect infections, autoimmune diseases and pathological process of tumors (26). STAT3 is an important nuclear transcription factor, the gene of which is located in chromosome 12 (27). STAT3 is widely expressed in various cells and tissues and is involved in the regulation of cell growth and differentiation, proliferation, apoptosis and other physiological functions (28). It was observed that embelin suppressed TNF- $\alpha$, IL-1 $\beta$, IL- 6 and IL-18 expression levels in AAA mice.

Currently, a large number of basic and clinical studies have verified that MMP-9 has an important role in the development process of AAA (29). AAA may lead to an increase of MMP-9 content in plasma and tumor wall tissue, however MMP-9 is a reliable indicator for judging AAA activity, which may be associated with the size of the AAA (29). The role of MMP-9 is not a static, however a dynamic process. The research and study regarding regulatory factors for the expression of MMP-9 activity and activation process, and the exploration of specific mechanisms, will lay the foundation for further understanding regarding AAA mechanism, drug treatment and prevention $(30,31)$. The results of the present study suggested that embelin treatment significantly suppressed the protein expression levels of MMP-9 in AAA mice.

CXCL5, additionally termed epithelial-derived neutrophil activating peptide 78 , is a member of the CXC chemokine family (32). CXCL5 has strong chemotaxis for inflammatory cells (including granulocytes and myeloid-derived suppressor cells) and a pro-angiogenesis effect, with an important role in the formation of the tumor microenvironment of inflammation, and is involved in tumor growth, invasion and metastasis (33). It has previously been demonstrated that CXCL5 is expressed in non-tumor tissues, including stomach disease, gastric mucosa, endometrial glands pulmonary fibrosis, inflammatory bowel disease, liver fibrosis and cirrhosis, which are associated with inflammatory damage; whereas in tumor tissues, including non-small cell lung, stomach, endometrial, prostate and pancreatic cancers, CXCL5 has a significantly increased expression compared with non-cancerous tissue $(34,35)$. CXCL5 may promote the development, angiogenesis and metastasis of non-small cell lung, stomach and endometrial cancers, in addition to AAA. CXCL5 is positively correlated with pathological grade, malignant degree and clinical stage of prostate cancer; high expression of CXCL5 also indicates that the patient has a poor prognosis (36). The results of the present study suggested that embelin significantly inhibited MCP-2 activity and CXCL5 levels in AAA model mice.

STAT3 gene is typically associated with the inflammatory response, and is located in the human chromosome 17 (q21) (37). Transcription factors NF- $\kappa$ B and STAT3 exhibit a key role in the process of cancer development promoted by inflammation. The stimulation and activation of NF- $\mathrm{KB}$ and STAT3 via inflammation may regulate transcription and expression of numerous genes, including those participating in the immune response, inflammation, cell proliferation and apoptosis (38). Under normal physiological conditions, the activation of NF- $\mathrm{KB}$ and STAT3 are strictly controlled, however in a variety of tumors, this control is destroyed with the appearance of abnormal activation, and regulation of the expression levels of a large number of genes conducive to tumor growth instead occurs (39). The present study observed that embelin significantly suppressed p-STAT3 protein expression in AAA mice. Dai et al (40). Demonstrated that embelin suppresses colitis-associated cancer by limiting IL-6/STAT3 activation and the T helper cell 17 immune response (37).

NF- $\mathrm{BB}$ links inflammation with cancer via the activation of the upstream molecule IKKP, which promotes the development of inflammation-associated tumors. Selectively inhibiting NF- $\kappa \mathrm{B}$ activation, will decrease rate of tumor development (41). It has been demonstrated that STAT3 and NF- $\mathrm{KB}$ have very important roles in the tumor development process promoted by inflammation. Blocking the activation of STAT3 and NF- $\mathrm{kB}$ signaling pathways via inflammatory cytokines will inhibit the local inflammatory response, and will result in the inhibition of the occurrence and development of inflammation-associated cancers, and provide a novel strategy with which to treat cancer $(42,43)$. The results of the present study demonstrated that embelin suppressed p-p38 and NF- $\kappa \mathrm{B}$ protein expression in AAA mice. Xu et al (14) suggested that embelin induces apoptosis through inhibition of p38 MAPK and NF- $\kappa$ B signaling pathways in human gastric carcinoma.

In conclusion, these data suggest that embelin inhibited the AAA incidence rate and decreased edge leading aortic diameter and aortic wall thickness in AAA mice via anti-inflammatory and anti-oxidation effects. Targeting IL-6-induced STAT3 and inactivation of NF- $\mathrm{\kappa B}$ will provide greater therapeutic potential in the treatment of AAA.

\section{Acknowledgements}

Not applicable.

\section{Funding}

No funding was received.

\section{Availability of data and materials}

The analyzed data sets generated during the study are available from the corresponding author on reasonable request. 


\section{Authors' contributions}

QW designed the experiment, QL and HL performed the experiment, QL and QW analyzed the data, and QW wrote the manuscript.

\section{Ethics approval and consent to participate}

The experiments were approved by the Animal Ethical and Welfare Committee of the First Hospital of Qiqiha'er (Qiqiha'er, China).

\section{Consent for publication}

Not applicable.

\section{Competing interests}

The authors declare that they have no competing interests.

\section{References}

1. Lal BK, Zhou W, Li Z, Kyriakides T, Matsumura J, Lederle FA and Freischlag J; OVER Veterans Affairs Cooperative Study Group: Predictors and outcomes of endoleaks in the Veterans Affairs Open Versus Endovascular Repair (OVER) trial of abdominal aortic aneurysms. J Vasc Surg 62: 1394-1404, 2015.

2. Li C, Li YS, Xu M, Wen SH, Yao X, Wu Y, Huang CY, Huang WQ and Liu KX: Limb remote ischemic preconditioning for intestinal and pulmonary protection during elective open infrarenal abdominal aortic aneurysm repair: A randomized controlled trial. Anesthesiology 118: 842-852, 2013.

3. Yang X, Chen YX, Zhang B, Jiang YX, Liu CW, Zhao RN, Wu Q and Zhang DM: Contrast-enhanced ultrasound in detecting endoleaks with failed computed tomography angiography diagnosis after endovascular abdominal aortic aneurysm repair. Chin Med J (Engl) 128: 2491-2497, 2015.

4. Karlsson L, Bergqvist D, Lindbäck J and Pärsson H: Expansion of small-diameter abdominal aortic aneurysms is not reflected by the release of inflammatory mediators IL-6, MMP-9 and CRP in plasma. Eur J Vasc Endovasc Surg 37: 420-424, 2009.

5. Jones KG, Brull DJ, Brown LC, Sian M, Greenhalgh RM, Humphries SE and Powell JT: Interleukin-6 (IL-6) and the prognosis of abdominal aortic aneurysms. Circulation 103: 2260-2265, 2001.

6. Kokje VBC, Gäbel G, Koole D, Northoff BH, Holdt LM, Hamming JF and Lindeman JHN: IL-6: A Janus-like factor in abdominal aortic aneurysm disease. Atherosclerosis 251: 139-146, 2016.

7. Liao M, Xu J, Clair AJ, Ehrman B, Graham LM and Eagleton MJ: Local and systemic alterations in signal transducers and activators of transcription (STAT) associated with human abdominal aortic aneurysms. J Surg Res 176: 321-328, 2012.

8. Banerjee K and Resat H: Constitutive activation of STAT3 in breast cancer cells: A review. Int J Cancer 138: 2570-2578, 2016.

9. Huang YH, Yang HY, Huang SW, Ou G, Hsu YF and Hsu MJ: Interleukin-6 induces vascular endothelial grow th factor- $\mathrm{C}$ expression via Src-FAK-STAT3 signaling in lymphatic endothelial cells. PLoS One 11: e0158839, 2016.

10. Bode JG, Albrecht U, Häussinger D, Heinrich PC and Schaper F: Hepatic acute phase proteins-regulation by IL-6and IL-1-type cytokines involving STAT3 and its crosstalk with NF-кB-dependent signaling. Eur J Cell Biol 91: 496-505, 2012.

11. He G and Karin M: NF- $\mathrm{BB}$ and STAT3-key players in liver inflammation and cancer. Cell Res 21: 159-168, 2011.

12. Dharmapatni AA, Cantley MD, Marino V, Perilli E, Crotti TN, Smith MD and Haynes DR: The X-linked inhibitor of apoptosis protein inhibitor embelin suppresses inflammation and bone erosion in collagen antibody induced arthritis mice. Mediators Inflamm 2015: 564042, 2015.
13. Marsh JL, Jackman CP, Tang SN, Shankar S and Srivastava RK: Embelin suppresses pancreatic cancer growth by modulating tumor immune microenvironment. Front Biosci (Landmark Ed) 19: 113-125, 2014

14. Xu CL, Zheng B, Pei JH, Shen SJ and Wang JZ: Embelin induces apoptosis of human gastric carcinoma through inhibition of p38 MAPK and NF-אB signaling pathways. Mol Med Rep 14: 307-312, 2016.

15. Huang CK, Luo J, Lai KP, Wang R, Pang H, Chang E, Yan C, Sparks J, Lee SO, Cho J and Chang C: Androgen receptor promotes abdominal aortic aneurysm development via modulating inflammatory interleukin-1 $\alpha$ and transforming growth factor- $\beta 1$ expression. Hypertension 66: 881-891, 2015.

16. Lederle FA, Freischlag JA, Kyriakides TC, Matsumura JS, Padberg FT Jr, Kohler TR, Kougias P, Jean-Claude JM, Cikrit DF and Swanson KM; OVER Veterans Affairs Cooperative Study Group: Long-term comparison of endovascular and open repair of abdominal aortic aneurysm. N Engl J Med 367: 1988-1997, 2012.

17. Wang GJ and Carpenter JP; Endologix Investigators: The powerlink system for endovascular abdominal aortic aneurysm repair: Six-year results. J Vasc Surg 48: 535-545, 2008.

18. Mahmoud KM and Ammar AS: effect of N-acetylcysteine on cardiac injury and oxidative stress after abdominal aortic aneurysm repair: A randomized controlled trial. Acta Anaesthesiol Scand 55: 1015-1021, 2011.

19. Takagi $\mathrm{H}$ and Umemoto $\mathrm{T}$ : The association between body mass index and abdominal aortic aneurysm growth: A systematic review. Vasa 45: 119-124, 2016.

20. Bruggink JL, Tielliu IF, Zeebregts CJ and Pol RA: Mesenteric ischemia after abdominal aortic aneurysm repair: A systemic review. J Cardiovasc Surg (Torino) 55: 759-765, 2014.

21. Mussa FF: Screening for abdominal aortic aneurysm. J Vasc Surg 62: 774-778, 2015.

22. Bergqvist D, Lindeman JH, Lindholt JS and Björck M: Antimicrobial treatment to impair expansion of abdominal aortic aneurysm (AAA): A systematic review of the clinical evidence. Curr Vasc Pharmacol 11: 288-292, 2013.

23. Honjo H, Kumagai Y, Ishiguro T, Imaizumi H, Ono T, Suzuki O, Ito T, Haga N, Kuwabara K, Sobajima J, et al: Heterotopic mesenteric ossification after a ruptured abdominal aortic aneurism: Case report with a review of literatures. Int Surg 99: 479-484, 2014.

24. Sbarzaglia P, Grattoni C, Oshoala K, Castriota F, D'Alessandro G and Cremonesi A: Aorfix ${ }^{\mathrm{TM}}$ device for abdominal aortic aneurysm with challenging anatomy. J Cardiovasc Surg (Torino) 55: 61-70, 2014.

25. Khashram M, Hider PN, Williman JA, Jones GT and Roake JA: Does the diameter of abdominal aortic aneurysm influence late survival following abdominal aortic aneurysm repair? A systematic review and meta-analysis. Vascular 24: 658-667, 2016.

26. Choudhury S, Gupta P, Ghosh S, Mukherjee S, Chakraborty P, Chatterji U and Chattopadhyay S: Arsenic-induced dose-dependent modulation of the NF- $\mathrm{KB} / \mathrm{IL}-6$ axis in thymocytes triggers differential immune responses. Toxicology 357-358: 85-96, 2016.

27. Lin C, Wang L, Wang H, Yang L, Guo H and Wang X: Tanshinone IIA inhibits breast cancer stem cells growth in vitro and in vivo through attenuation of IL-6/STAT3/NF-kB signaling pathways. J Cell Biochem 114: 2061-2070, 2013.

28. Ma W, Sze KM, Chan LK, Lee JM, Wei LL, Wong CM, Lee TK, Wong CC and Ng IO: RhoE/ROCK2 regulates chemoresistance through NF- $\kappa \mathrm{B} / \mathrm{IL}-6 / \mathrm{STAT} 3$ signaling in hepatocellular carcinoma. Oncotarget 7: 41445-41459, 2016.

29. Duellman T, Warren CL, Peissig P, Wynn M and Yang J: Matrix metalloproteinase-9 genotype as a potential genetic marker for abdominal aortic aneurysm. Circ Cardiovasc Genet 5: 529-537, 2012.

30. Adovasio R, Calvagna C, Sgorlon G, Zamolo F, Mearelli F, Biolo G, Grassi G and Fiotti N: Growth rate of small abdominal aortic aneurysms and genetic polymorphisms of matrix metalloProteases-1, -3 and -9. Int J Angiol 25: 93-98, 2016.

31. Tazume H, Miyata K, Tian Z, Endo M, Horiguchi H, Takahashi O, Horio E, Tsukano H, Kadomatsu T, Nakashima Y, et al: Macrophage-derived angiopoietin-like protein 2 accelerates development of abdominal aortic aneurysm. Arterioscler Thromb Vasc Biol 32: 1400-1409, 2012.

32. Wang LY, Tu YF, Lin YC and Huang CC: CXCL5 signaling is a shared pathway of neuroinflammation and blood-brain barrier injury contributing to white matter injury in the immature brain. J Neuroinflammation 13: 6, 2016. 
33. Madalli S, Beyrau M, Whiteford J, Duchene J, Singh Nandhra I, Patel NS, Motwani MP, Gilroy DW, Thiemermann C, Nourshargh S and Scotland RS: Sex-specific regulation of chemokine Cxcl5/6 controls neutrophil recruitment and tissue injury in acute inflammatory states. Biol Sex Differ 6: 27, 2015.

34. Zhu X, Qiao Y, Liu W, Wang W, Shen H, Lu Y, Hao G, Zheng J and Tian Y: CXCL5 is a potential diagnostic and prognostic marker for bladder cancer patients. Tumour Biol 37: 4569-4577, 2016.

35. Gao Y, Guan Z, Chen J, Xie H, Yang Z, Fan J, Wang X and Li L: CXCL5/CXCR2 axis promotes bladder cancer cell migration and invasion by activating PI3K/AKT-induced upregulation of MMP2/MMP9. Int J Oncol 47: 690-700, 2015.

36. Song J, Wu C, Zhang $X$ and Sorokin LM: In vivo processing of CXCL5 (LIX) by matrix metalloproteinase (MMP)-2 and MMP-9 promotes early neutrophil recruitment in IL-1 $\beta$-induced peritonitis. J Immunol 190: 401-410, 2013.

37. Yang DJ, Chang YY, Lin HW, Chen YC, Hsu SH and Lin JT: Inhibitory effect of litchi (Litchi chinensis Sonn.) flower on lipopolysaccharide-induced expression of proinflammatory mediators in RAW264.7 cells through NF- $\kappa$ B, ERK, and JAK2/STAT3 inactivation. J Agric Food Chem 62: 3458-3465, 2014.

38. Hendrayani SF, Al-Harbi B, Al-Ansari MM, Silva G and Aboussekhra A: The inflammatory/cancer-related IL-6/STAT3/NF- $\kappa$ B positive feedback loop includes AUF1 and maintains the active state of breast myofibroblasts. Oncotarget 7 : 41974-41985, 2016.
39. Hsieh YJ, Tseng SP, Kuo YH, Cheng TL, Chiang CY, Tzeng YM and Tsai WC: Ovatodiolide of anisomeles indica exerts the anticancer potential on pancreatic cancer cell lines through STAT3 and NF- $\kappa$ B regulation. Evid Based Complement Alternat Med 2016: 8680372, 2016.

40. Dai Y, Jiao H, Teng G, Wang W, Zhang R, Wang Y, Hebbard L, George J and Qiao L: Embelin reduces colitis-associated tumorigenesis through limiting IL-6/STAT3 signaling. Mol Cancer Ther 13: 1206-1216, 2014.

41. Liu YF, Bai YQ and Qi M: Daidzein attenuates abdominal aortic aneurysm through NF- $\kappa \mathrm{B}, \mathrm{p} 38 \mathrm{MAPK}$ and TGF- $\beta 1$ pathways. Mol Med Rep 14: 955-962, 2016.

42. Tsai SH, Huang PH, Peng YJ, Chang WC, Tsai HY, Leu HB, Chen JW and Lin SJ: Zoledronate attenuates angiotensin II-induced abdominal aortic aneurysm through inactivation of Rho/ROCK-dependent JNK and NF- $\kappa$ B pathway. Cardiovasc Res 100: 501-510, 2013

43. Yu Q, Zeng K, Ma X, Song F, Jiang Y, Tu P and Wang X: Resokaempferol-mediated anti-inflammatory effects on activated macrophages via the inhibition of JAK2/STAT3, NF- $\mathrm{BB}$ and JNK/p38 MAPK signaling pathways. Int Immunopharmacol 38: 104-114, 2016 